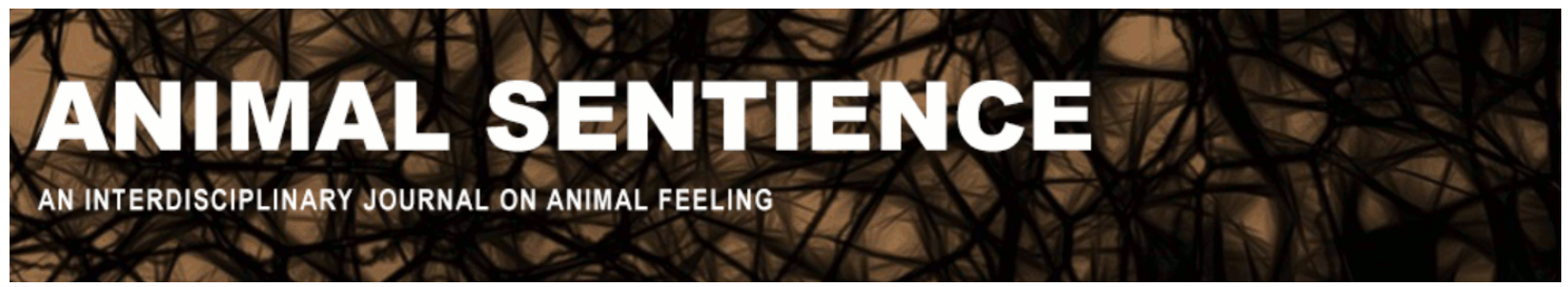

Woodford, Peter and Carter, Alecia (2019) Science, social critique, and the need for ethics. Animal Sentience 25(34)

DOI: $10.51291 / 2377-7478.1466$

Date of submission: 2019-05-29

Date of acceptance: 2019-06-10 (c) 


\title{
Science, social critique, and the need for ethics
}

Commentary on Marino \& Merskin on Sheep Complexity

\author{
Peter Woodford \\ Department of Religious Studies \\ Union College, Schenectady
}

\author{
Alecia Carter \\ Institute des Sciences de l'Évolution de Montpellier (ISEM) \\ Université de Montpellier, CNRS, IRD, EPHE, Montpellier, France
}

\begin{abstract}
Marino \& Merskin's target article on the cognitive and psychological capacities of sheep commendably aims to use science to critique human practice. However, the article fails to make specific recommendations about how human-sheep relations should change going forward. We also underscore two problematic assumptions highlighted by other commentators: (1) that cognitive complexity is important to the case for the moral status of non-human animals and (2) that the way humans use and treat animals is caused by our conception of animals' capacities. Scientists should engage more with philosophy and ethical theory to articulate the implications of animal capacities for human treatment of animals.
\end{abstract}

Peter Woodford is an Assistant Professor at Union College, Schenectady, NY. His research focuses on the intersection of science and ethics, the evolutionary foundations of ethical values, scientific research on altruism and cooperation, and the relationship between science and religion. Website

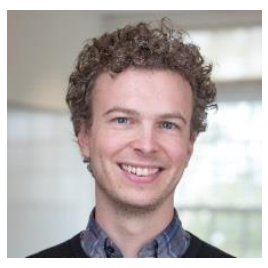

Alecia Carter is a research scientist with the Centre National de la Recherche Scientifique at I'Université des Sciences de l'Évolution de Montpellier. Her research investigates how animals acquire and use information to make decisions. Website

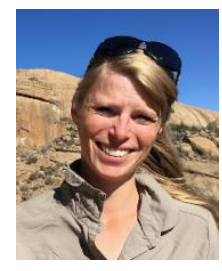

Marino \& Merskin's (M\&M) (2019) article on the cognitive and psychological capacities of sheep is a good illustration of an attempt to use science to critique ideology and human practice. If ideology is a view of reality that supports and legitimizes a set of social practices, and indeed hides aspects of reality from view that might challenge the moral acceptability of such practices, then the notion that sheep are simple-minded, passive, obedient, and dependent - lower beings on an ontological scala naturae - might be the ideology that allows those who mistreat sheep to sleep at night. In that way, as M\&M put it, (recent) historical perceptions of sheep may "fuel and sustain contemporary media, popular culture, and farming practices" (p. 16). 
M\&M hope that their review will lead to "reconsidering the use of sheep as commodities in modern agricultural production and in invasive research" (p. 16). However, the nature of this reconsideration is left largely vague; and $M \& M$ do not outline what an ethical relationship with sheep concretely requires. To do so would require defending an ethical theory and showing how it applies in this case, which would benefit from engagement with literature in the field of animal ethics.

To illustrate this, we point out that M\&M's argument appears to be implicitly abolitionist; that is, it supports the position that humans should "free" sheep and cease using them for resources or for research. This abolitionist stance, however, does not obviously follow from the facts about sheep psychology that M\&M illuminate. Abolitionism is particularly problematic given that domestic sheep exist because of human artificial selection. Horback (2019) illustrates an alternative conclusion, namely, that sheep need human intervention because they are a domesticated species: that it is arguably unethical to "re-wild" them and certainly unethical to simply set them free when some breeds need human intervention. An abolitionist stance thus requires much more argument and defense.

If $M \& M$ intended to defend a more moderate position - one that minimizes the infliction of unjustifiable suffering on sentient beings - more could have been done in the review to define what it means to mistreat sheep given what is known of sheep's abilities. That is, what constitutes minimal justifiable suffering? $M \& M$ do not take a clear stance on the more challenging moral questions: Would it be morally permissible under certain levels of care and minimization of suffering to use sheep for wool, milk, meat or scientific research? What extent of suffering might be morally acceptable? How does our knowledge of sheep psychological complexity help us determine the conditions under which sheep suffer in indefensible ways? The answers to these questions are often difficult. There is room for reasonable disagreement, and the morally relevant factors of specific cases require analysis. For example, there is no way to minimize suffering in industrial farming where most attention is paid to minimizing cost and maximizing output. But in a system where sheep that live their lives on small-scale farms where they are known individually and habituated to being handled, one could argue that suffering is minimized enough for use of their wool and milk. But what about the use for leather and meat?

M\&M also claim that psychological complexity is the capacity upon which the moral status of sheep rests. We would second Browning's (2019) and Palmer \& Sandøe's (2019) point that none of the leading theories in animal ethics rest their case on psychological complexity or intelligence. To do so would be to endorse an anthropocentric picture that animal ethics as a field has sought to discredit. Instead, the minimal capacity that matters to most ethicists is sentience, defined as the ability to experience pleasure or pain, or as Regan (1983, p. 243) put it: having an experiential life that can go well or badly.

As Vonk (2019) and Horback (2019) also point out, the focus on complexity is incoherent given the critique of anthropocentrism $M \& M$ try to make: frustratingly, $M \& M$ allude to the morally relevant capacities of sheep through comparisons to taxa that are putatively given higher moral regard because of their intelligence, such as primates. But even if sheep were in fact "simple" and obedient, this would in no way entail that it was permissible to harm them, just as the varying mental capacities of other human beings have no relevance for whether we are morally obligated not to harm them (Singer, 2015). This is a crucial point in the case for the moral status of animals. 
Another questionable assumption is one that is widely made in areas of environmental ethics and animal ethics, and has been made by several other commentators on this target article (Baker, 2019; Davis, 2019; Palmer \& Sandøe, 2019). M\&M claim that they are challenging a view - that sheep are "less" than other animals - which allows people to "psychologically distance" themselves from the animals they use for resources. If the source of cruelty to animals lies in the false or even self-deceptive belief that humans have no moral obligations to animals or the rest of nature because they are "lower," then the solution to the problem lies in correcting this belief. Whether humans are more likely to treat animals better if they come to reject the scala naturae, however, is an empirical claim about human psychology and behavior that we cannot yet support on the basis of evidence. Moreover, there are prima facie reasons to be skeptical:

Humans have strong material interests in the resources sheep offer. This is probably the major reason they were domesticated in the first place - and the reason factory farming exists today. Of course, having a strong material interest may also mean that there is a strong interest in rejecting moral arguments and in "rationalizing" bad behavior. But humans are also cruel to other humans, and there is a general problem that humans often fail to do what they consider to be morally right. This is not at all to suggest that anthropocentrism is correct, or that challenging it is not at least an important part of what it will take to bring human-animal relationships into an ethically justifiable state. But M\&M's critique is not sensitive enough to the more complex institutional, psychological, and economic factors that contribute to the use of animals for the sake of humans. Seen in this light, the fact that sheep are viewed as "obedient, passive, and uniform" may not play a decisive role in our best psychological explanation of why they are mistreated.

To be clear, we agree that domesticated animals are treated abhorrently in mass farming practices and in some areas of research, that this mistreatment arises in part through psychological-cognitive mechanisms that will be difficult to overcome, and that much could be done to improve domestic animals' lives. However, M\&M's target article largely bypasses the hard questions and misses an opportunity to specify more concretely what it means to mistreat sheep. Drawing out the ethical implications of scientific work on animal cognition and psychology requires deeper engagement with ethical theory.

\section{References}

Baker, L. (2019). Is knowing enough to change human attitudes and actions? Animal Sentience 25(4).

Browning, H. (2019). What should we do about sheep? The role of intelligence in welfare considerations. Animal Sentience 25(23).

Davis, H. (2019). Our disparaging view of sheep is indeed based on cognitive inadequacy: Unfortunately, it's ours. Animal Sentience 25(20).

Horback, K. (2019). Applied cognition research to improve sheep welfare. Animal Sentience 25(18).

Marino, L., \& Merskin, D. (2019). Intelligence, complexity, and individuality in sheep. Animal Sentience 25(1).

Palmer, C., \& Sandøe, P. (2019). Yes, sheep are smart but the moral question is still 'do they suffer'? Animal Sentience 25(24).

Regan, T. (1983). The case for animal rights. Berkeley: University of California Press.

Singer, P. (2015). Animal liberation: The definitive classic of the animal movement. Open Road Media. Vonk, J. (2019). Pulling the wool from our eyes. Animal Sentience 25(3). 